\title{
Knowledge and Practices of Preventive Sexual and Reproductive Health Behaviours Among Male Civil Servants in Southwestern Nigeria
}

\author{
Adewusi Oluwafemi John*, Oyewole Oyediran Emmanuel \\ Department of Health Promotion and Education, University of Ibadan, Ibadan, Nigeria \\ Email address: \\ hadewusy@gmail.com (A. O. John), diranoyewole@gmail.com (O. O. Emmanuel) \\ ${ }^{*}$ Corresponding author
}

\section{To cite this article:}

Adewusi Oluwafemi John, Oyewole Oyediran Emmanuel. Knowledge and Practices of Preventive Sexual and Reproductive Health Behaviours Among Male Civil Servants in Southwestern Nigeria. European Journal of Preventive Medicine.

Vol. 5, No. 6, 2017, pp. 91-96. doi: 10.11648/j.ejpm.20170506.13

Received: September 1, 2017; Accepted: September 22, 2017; Published: November 27, 2017

\begin{abstract}
Men's leading trend in risky sexual practices and non-utilization of screening services has been associated with their perceived risk of sexually transmitted infections. This study assessed the preventive sexual and reproductive health knowledge, perception and practice of men in the southwestern Nigeria. This was a descriptive cross-sectional that used a fourstage sampling technique to select 272 male civil servants still in service and randomly selected across 14 Ministries in Oyo State Secretariat, Ibadan, located in the Southwest of Nigeria. A pre-tested semi-structured self-administered questionnaire, which contained a 18-point knowledge scale, 26-point perception scale and 12-point practice scale were used for data collection and the data were analyzed using descriptive statistics and Chi-square test at $p=0.05$. Respondents' age was $38.0 \pm$ 9.4 years. The respondents' knowledge was fair but perception and practice of preventive sexual and reproductive health behaviours were poor. There was significant relationship between the age, cadre of the respondents and the knowledge of preventive sexual and reproductive health behaviour but there was no significant relationship between knowledge and perception. Health promotion and education strategies to promote good preventive sexual and reproductive health practices should be designed for the men.
\end{abstract}

Keywords: Preventive Health Behaviours, Male Civil Servants, Reproductive Health

\section{Introduction}

Evidences consistently show that men seek help less often than women and underutilize medical and health services and this has been linked to masculine gender socialization in the society [1-3]. Men generally show lackadaisical attitude in taking care of their health including sexual and reproductive health and male-focused preventive or health promoting care is usually not provided [4-6].

For instance, the National Demographic Health Survey (NDHS), a national health document in Nigeria which contains many preventive sexual and reproductive health variables such as current use of contraceptives, high risk fertility behaviour, access to health care, nutritional and diet behaviour are targeted towards women and children, neglecting the male population. Some of the few available indicators reported in the NDHS 2013 show that the men folk were highly at risk of diseases due to the exhibition of negative health behaviours such as sexual risky practices, smoking and tobacco use, non-engagement with preventive care, poor uptake of health care services.

"Men in Nigeria suffer the highest burden from prostate cancer with an estimated annual age-adjusted incidence and mortality rates of 22.7 and 18.6 per 100,000 , respectively. This accounts for $18.2 \%$ and $17.7 \%$, respectively of all cancer-related diagnoses and deaths, in men in this region. Given that Nigeria is the most populous country in Africa with an estimated population of 160 million in 2012, the rates and percentages above translate to an enormous burden in absolute numbers of men affected by Prostate Cancer" [7]. 
However, men's healthy living is not only essential for them but also for the entire nation since they are leaders in the family and community acting as husbands, uncles, religious leaders, government officials [4, 5] [8]. Cultural and societal beliefs and expectations tend to make men responsible for making sexual and reproductive health decisions that is, deciding when, where and how sex will take place. This heightens not only men's but also women's vulnerability to HIV/AIDS and other sexually transmitted infections [9]. Therefore, even though women bear the heaviest burden of sexual and reproductive health challenges, men are critical in determining the extent of this burden.

This study, therefore aimed at investigating the knowledge and practice of men working in the Oyo State Secretariat, Ibadan, Oyo State.

\section{Methodology}

The study was a descriptive cross-sectional study utilizing semi-structured self-administered questionnaire conducted among male civil servants in Oyo State Secretariat, Ibadan. Two hundred and seventy-two men within the age range of $18-60$ years still in service with the Oyo State Government in the State Secretariat and willing to give an informed consent were selected using the multi-stage sampling technique.

A pre-tested semi-structured self-administered questionnaire consisting of four sections was used. The first section was to elicit socio-demographic information while knowledge of male civil servants on preventive sexual and reproductive health behaviour; perception of male civil servants towards preventive sexual and reproductive health behaviour and preventive sexual and reproductive health practices among the male civil servants made up sections two, three, and four respectively.

An 18-point knowledge scale was developed and 0-6 was categorized as poor knowledge while 7-12 and $>12$ were categorized as fair and good knowledge, respectively. A 26point perception scale was used and $0-13$ and $>13$ were categorized as poor and good perception, respectively. Similarly, a 12-point practice scale was used to measure practice of preventive sexual and reproductive health behavior. Scores 1-6 and $>6$ were categorized as poor and good practice, respectively.

Ethical approval for the study was obtained from the Oyo State Ministry of Health Ethical Review Committee. Permission was taken from the Head of Service. Privacy, anonymity and confidentiality were ensured in administering the questionnaires.

\section{Results}

\subsection{Socio-demographic Characteristics}

Age distribution of the respondents ranged from 19 to 60 years with the mean age as $38.0 \pm 9.4$ years. Majority, $(71.0 \%)$ were married and $51.5 \%$ had first degree. More than half, (59.9\%) were senior staff.

Table 1. Socio-demographic Characteristics of Respondents.

\begin{tabular}{|c|c|c|c|}
\hline$(n=272)$ Variables & & Frequency & Percentage \\
\hline \multirow{3}{*}{ Age } & 18-29 years & 55 & 20.2 \\
\hline & $30-41$ years & 114 & 41.9 \\
\hline & 42 and above & 89 & 32.7 \\
\hline \multirow{4}{*}{ Marital Status } & Single & 76 & 27.9 \\
\hline & Married & 193 & 71.0 \\
\hline & Divorced & 2 & 0.7 \\
\hline & Separated & 1 & 0.4 \\
\hline \multirow{5}{*}{ Educational Qualification } & Primary School Certificate & 6 & 2.2 \\
\hline & SSCE & 33 & 12.1 \\
\hline & N.C.E/O.N.D & 63 & 23.2 \\
\hline & H.N.D./B.Sc/B.Ed/B.A & 140 & 51.4 \\
\hline & M.Sc/M.Ed/M.A & 28 & 10.3 \\
\hline \multirow{2}{*}{ Cadre } & Senior Staff & 163 & 59.9 \\
\hline & Junior Staff & 107 & 39.3 \\
\hline
\end{tabular}

\subsection{Knowledge of STIs Preventive Behaviour}

The average knowledge of preventive sexual and reproductive health behaviours was fair $(8.7 \pm 3.7)$. Only $16.2 \%$ had good knowledge of preventive sexual behaviours while $55.9 \%$ had fair and $27.9 \%$ had poor knowledge, respectively. About half (55.9\%) had good knowledge of sexually transmitted infections while $30.5 \%$ had fair knowledge and $13.6 \%$ had poor knowledge of STIs. Majority of the men $(64.0 \%)$ had no knowledge of risky sexual practices. However, $70.2 \%$ knew the advantages of using condom.

Majority of the men (64.3\%) did not know why it is unhealthy for men to put on tight underwear. Likewise, $59.2 \%$ did not know any personal hygiene practice for the male reproductive organs that could prevent infections. Respondents $(53.3 \%)$ knew at least one place to do HIV screening and only $43.0 \%$ gave at least one good reason for HIV screening. Majority (78.7\%) did not know at what age a man should go for prostate cancer screening. 


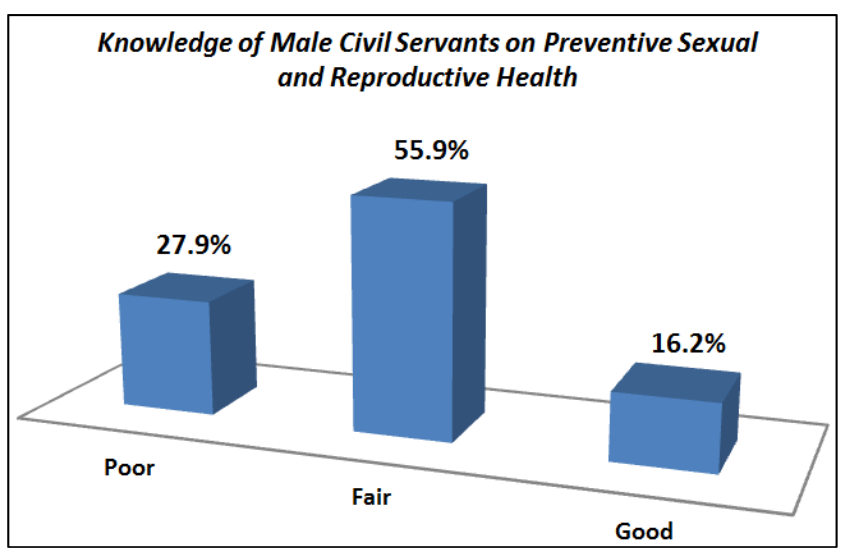

Figure 1. Knowledge of Preventive Sexual and Reproductive Health.

\subsection{Perception of STIs Preventive Behaviour}

Some, $45.6 \%$ and $44.5 \%$, respectively still agreed with the fact that STIs affect only women and could be caused by witches. This study showed that $51.8 \%$ disagreed with the perception that STIs will go if not treated. Majority, (88.2\%) agreed that condom use can prevent pregnancy and also $89.7 \%$ agreed that condom is not difficult to use. Respondents $(95.2 \%)$ agreed that condom is readily available to buy. However, $41.9 \%$ agreed that condom has side effects on their body while $48.9 \%$ agreed that trying to use condom can be time wasting during initiation of sexual intercourse. Also, $46.7 \%$ agreed that condom can limit sexual pleasure and $55.9 \%$ disagreed with the perception that herbal concoction is more effective in treating STIs than conventional STI drugs.

Some men (42.6\%) agreed that having sex with other men maybe more enjoyable while $44.9 \%$ felt it is not possible for them to be faithful to one sexual partner. Half of the men (51.1\%) disagreed with the fact that prostate cancer screening is meant only for wealthy men while $63.6 \%$ perceived themselves to be susceptible to prostate cancer. However, only $47.1 \%$ agreed that they are susceptible to STIs or HIV. Only $45.6 \%$ perceived that late detection of STIs can cause infertility while $41.5 \%$ and $18.0 \%$ perceived going for HIV and prostate cancer screenings as a waste of time, respectively. Also, $44.9 \%$ perceived that reporting every abnormal sign in their reproductive organs to the hospital is a sign of being fearful.

Some men $(43.8 \%)$ said they were too busy to go for HIV/STIs screening regularly while $44.9 \%$ said health workers waste their time when they go for HIV/STIs screening, which has discouraged them. Majority, (82.4\%) agreed that dirty underwear could predispose them to reproductive organ infections while $44.1 \%$. agreed that examining the penis and scrotum daily is unnecessary. Majority, (66.9\%) agreed that washing the scrotum and penis with soap and water regularly could prevent infections while $51.5 \%$ agreed that tight underwears could affect sperm quality. The average perception of preventive sexual and reproductive health behaviours was poor $(10.7 \pm 5.7)$ with $62.5 \%$ having poor perception.

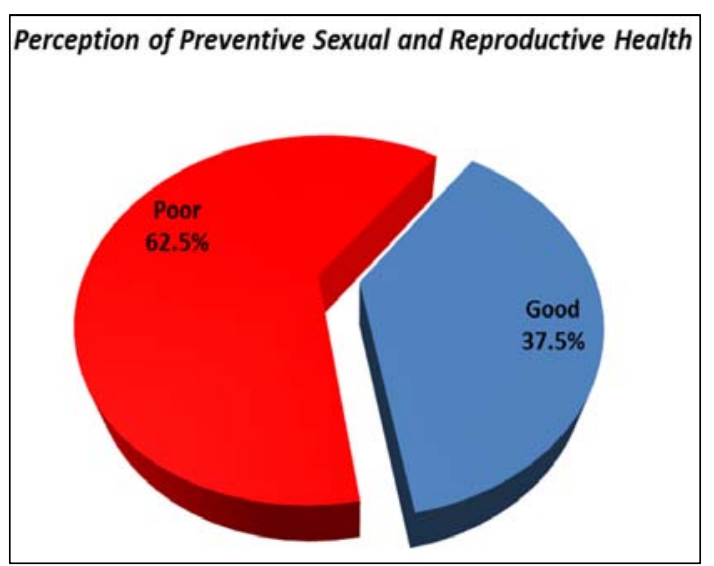

Figure 2. Perception of Preventive Sexual and Reproductive Health.

\subsection{Practice of STIs Preventive Behaviour}

Some of the respondents (39.3\%) had more than one sexual partner while $46.0 \%$ used condom for sexual intercourse with their other sexual partners. Up to $38.6 \%$ of the men said they had sex with other men while $11.4 \%$ gave no response to this. Few of the men (35.3\%) used herbal concoction when they see signs of STIs while only $43.4 \%$ and $43.8 \%$ had undergone prostate cancer screening in the last one year and HIV screening in the last three months, respectively. Most of the men (84.9\%) washed their reproductive organs with soap and water daily while $76.8 \%$ changed their underwear daily and $72.8 \%$ examined their scrotum and penis regularly but $47.4 \%$ sometimes wore tight underwear. Average practice of preventive sexual and reproductive health behaviours was poor $(5.3 \pm 2.0)$ with $77.6 \%$ having poor practices.

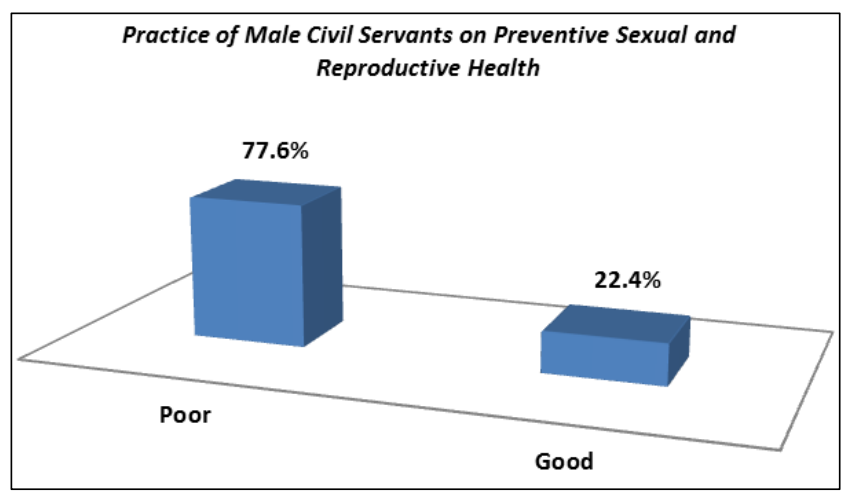

Figure 3. Practice of Preventive Sexual and Reproductive Health.

\subsection{Test of Hypotheses}

Results show that the knowledge of preventive sexual and reproductive health behaviours was statistically significant with age $\left(\mathrm{X}^{2}=12.496, \mathrm{df}=6, \mathrm{p}=0.050\right)$ and also with cadre, with men in the higher cadre showing better knowledge of preventive sexual and reproductive health behavior $\left(\mathrm{X}^{2}=\right.$ $16.553, p=0.002$ ). However, perception of preventive sexual and reproductive health behaviour among respondents was not significantly associated with knowledge $\left(X^{2}=0.760, \mathrm{df}=\right.$ $2, \mathrm{p}=0.688)$. 
Table 2. Relationship between Knowledge of preventive sexual and reproductive health behaviour and Age of Respondents.

\begin{tabular}{|c|c|c|c|c|c|}
\hline \multirow{2}{*}{$\begin{array}{l}\mathrm{N}=272 \\
\text { Age (years) }\end{array}$} & \multicolumn{5}{|l|}{ Knowledge } \\
\hline & Poor n(\%) & Fair n(\%) & Good n(\%) & $\mathrm{X}^{2}$ & $\mathbf{p}$ \\
\hline $18-29$ years & $25(9.2 \%)$ & $24(8.8)$ & $6(2.2)$ & 12.496 & 0.050 \\
\hline $30-41$ years & $31(11.4)$ & $63(23.2)$ & $20(7.4)$ & & \\
\hline$\geq 42$ & $17(6.2)$ & $56(20.6)$ & $16(5.9)$ & & \\
\hline
\end{tabular}

Table 3. Relationship between Knowledge of preventive sexual and reproductive health behaviour and Cadre.

\begin{tabular}{lllll}
\hline $\mathbf{N}=\mathbf{2 7 2}$ & Knowledge & & & \\
\cline { 2 - 5 } Cadre & Poor $\mathbf{n}(\%)$ & Fair $\mathbf{n}(\mathbf{\%})$ & Good $\mathbf{n}(\mathbf{\%})$ & $\mathbf{\mathbf { X } ^ { 2 }}$ \\
\hline Senior Staff & $34(12.5)$ & $94(34.6)$ & $35(12.9)$ & 16.553 \\
Junior Staff & $42(15.4)$ & $56(20.6)$ & $9(3.3)$ & 0.002 \\
\hline
\end{tabular}

Table 4. Relationship between Knowledge and Perception on preventive sexual and reproductive health behaviour.

\begin{tabular}{|c|c|c|c|c|c|}
\hline \multirow{2}{*}{$\begin{array}{l}\mathrm{N}=272 \\
\text { Perception }\end{array}$} & \multicolumn{5}{|l|}{ Knowledge } \\
\hline & Poor n(\%) & Fair n(\%) & Good n(\%) & $\mathrm{X}^{2}$ & $\mathbf{p}$ \\
\hline Poor & $46(16.9)$ & $94(34.6)$ & $30(11.0)$ & 0.760 & 0.688 \\
\hline Good & $30(11.0)$ & $58(21.3)$ & $14(5.1)$ & & \\
\hline
\end{tabular}

\section{Discussion}

The age distribution represented a young workforce and the proportion of the graduates was similar to the findings of Ibrahim [10] in a study conducted among the same population. Many of the respondents were senior staff, corroborating the National Bureau of Statistics report [11].

\subsection{Knowledge of STIs Preventive Behaviour}

This study identified a considerable fair knowledge of preventive sexual and reproductive health behaviours unlike other studies conducted on Diabetes among civil servants in Nigeria [12]. However, findings in this study revealed that the men have good knowledge of condom, which supports the findings of other studies [13-15]. Over half of the men had the knowledge of a place to go for HIV screening in this study and corroborates the NDHS 2013 report for men in Oyo State. The knowledge of the recommended age for prostate cancer screening was very low similar to other previous studies $[16,17]$.

\subsection{Perception of STIs Preventive Behaviour}

Although, this study revealed a good perception about condom as an available, cheap and easy-to-use contraceptive which was probably influenced by knowledge of condom, some men agreed that it can limit sexual pleasure. This perception is not only limited to men but also to women and this perception was vital to the acceptance and use of condom by these men as several men had the desire to preserve their sexual pleasure and comfort [14] [18]. In addition, few men also believed that condom has side effects after use. This is an identified barrier to condom use in Nigeria [18]. Beliefs exist that condom can be a source of virginal dryness, inflammation and disease and some men described condom as a coffin, arguing that condom has negative effects on women; condoms could cause them a disease and that the woman's womb could become dry after repeated use [18]. A good proportion of the men perceived themselves to be susceptible to prostate cancer and HIV and this is dissimilar with previous study conducted among men in Kenya where only few of the men had poor perception on self-vulnerability to prostate cancer [19].

Majority of the men had poor perception of preventive sexual and reproductive health behaviours, which is similar to previous findings by other study [20].

\subsection{Practice of STIs Preventive Behaviour}

More than one-third of the men had multiple sexual partners and did not use condom for sexual intercourse with other sexual partners despite high knowledge about the benefits of condom. This is similar to findings from previous studies where men were shown to engage in multiple sexual partnering [15] [21-23]. The low level of condom use may not be unconnected with the poor perception of condom as limiting sexual pleasure and having side effects on their body. Studies conducted in other developing countries showed evidences of similar disparities between high levels of knowledge of HIV/AIDS and awareness of condom and lower use of condoms as a method of disease and pregnancy prevention [24, 25].

Few men have sex with other men and some men gave no response to this question. This may be due to the fear of social stigma and criminalization, which may lead to arrest. The UNAIDS reports that there are currently, inadequate data on the prevalence of homosexuals globally especially in Africa [26].

Half of the men had not undergone prostate cancer screening in the last one year and HIV screening in the last three months. This was corroborated by other studies [16] [27]. However, majority wash their reproductive organs with soap and water and changed their underwear daily. This is probably due to the fact that bathing is customarily perceived as a daily morning activity.

The educational qualification was significantly associated with the knowledge of preventive sexual and reproductive 
health behaviours. This is in agreement with previous studies $[28,29]$. However, the age was not statistically associated with their knowledge of preventive sexual and reproductive health behaviours. This is dissimilar with other similar findings whose study revealed a significant association between age and knowledge of complications in diabetes management among civil servants in Anambra State [12].

\section{Conclusion and Recommendations}

Fair knowledge of preventive sexual and reproductive health behaviours was observed among men and this may influenced men's perception and consequently poor practice as far as preventive and reproductive health is concerned. In view of these findings, the following recommendations can become relevant; creation of awareness through the use of Information, Education and Communication (IEC) materials such as handbills and posters in the offices with information on these issues. This can be pasted in strategic places in each Ministry at the Secretariat. Preventive sexual and reproductive health seminars and workshops can also be organized for workers in the Ministry. Policies to promote the adoption of these preventive sexual and reproductive health behaviours should be formulated by the government and adhered to by all relevant stakeholders. Programmes and interventions that will increase the knowledge and promote the adoption of these behaviours should be designed and implemented by the government and non-governmental organizations and other stakeholders. The workplace health promotion strategies will be good approach in creating more awareness for positive behaviour change.

\section{Acknowledgements}

The authors wish to acknowledge the Head of Service and the entire staff of Oyo State Secretariat who are the participants in this study.

\section{Conflict of Interest}

The authors wish to declare no conflict of interest whatsoever.

\section{References}

[1] Mansfield, A. K., Addis, M. E., Mahalik, J. R. (2003). “Why Won't He Go to the Doctor?" The Psychology of Men's Help Seeking. International Journal of Men's Health, 2:2, 93-109.

[2] Addis, M. E., \& Mahalik, J. R. (2003). Men, masculinity and the contexts of help seeking. American Psychologist, 58:1, 5-14.

[3] Benett, G. (Ed)., Rosalind, J. (Ed)., (2006). From the guest editors--Men, masculinity, and mental health. Issues Ment., Health Nurs., 27:4, 333-336.

[4] United Nation (1992). Fertility behaviour in the Context of development: Evidence from the World Fertility Survey. New York: Department of International Economic and Social
Affairs.

[5] Galdas, P. M., Cheater, F., and Marshall, P. (2004). Men and health help-seeking behaviour: Literature Review. Journal of Advanced Nursing, 49(6), 616-623.

[6] Jeanfreau S. G. (2011) Is Anyone Promoting the Health of Men? American Journal of Men's Health 5(4) 285.

[7] Olufemi Ogunbiyi (2014). Nigeria Prostate Cancer Research Symposium. Covenant University, Nigeria.

[8] European Commission. (2011). The state of men's health in Europe report.

[9] Quincey Efiong Asanaenyi (2014) A Gender Analysis of Nigeria's Millennium Development Goals Implementation Reports. Unpublished Masters Thesis submitted to the Department of Theatre and performing Art, Ahmadu Bello University, Zaria.

[10] Ibrahim, F. M. (2011). Fruity Response Efficacy and Fruit Consumption among a Group of Civil Servants of Oyo State, Nigeria. Am. J. Food. Nutr, 1(1): 44-48.

[11] National Bureau of Statistics (2014). Statistical Report on Women and Men in Nigeria, pp. 5-8.

[12] Uloma A., Maurice C. A., Godswill A. N., Dennis O. U. (2014). Socio-demographic determinants of the knowledge of diabetes mellitus in Onitsha-North Local Government Area, Anambra State. Orient Journal of Medicine, Vol 26 (1-2).

[13] National AIDS/STI Control Programme (NACP) (2011), HIV Sentinel Survey and National HIV Prevalence. Progress Report. Accra: Ghana health service.

[14] Daniel Yaw Fiaveh (2012). Condom Myths and Misconceptions: The Male Perspective. Global Journal of Medical research Vol. 12 Issue 5 Version 1.0.

[15] National Population Commission (NPC) (Nigeria) and ICF International (2014). Nigeria Demographic and Health Survey 2013. Abuja, Nigeria, and Rockville, Maryland, USA: NPC and ICF International.

[16] Abdulwahab A. A., Abdulateef B. and Olusegun O. A. (2010). Knowledge of prostate cancer screening among Native African Urban Population in Nigeria. Nig. Qt J. Hosp. Med. Vol. 20(2).

[17] Nathaniel Mofolo., Olwethu Betshu, Ogomoditse Kenna, Sarah Koroma, Tlalane Lebeko, Frederik M Claassen and Gina Joubert (2015). Knowledge of prostate cancer among males attending a urology clinic, a South African study. Springer Plus. 4:67.

[18] Iyaji A. and Ogbuke M. U. (2011). Condom Use in Nigeria: An Evaluation. Current Research Journal Economic Theory 3(1): 10-13

[19] Wanyagah P. (2013). Prostate Cancer Awareness, Knowledge, Perception on Self Vulnerability and Uptake of Screening among Men in Nairobi County, Kenya. An online research thesis submitted to the school of Public Health in partial fulfilment of the requirements for the award of the degree of Master of Health Management of Kenyatta University.

[20] Igbalajobi A. O., Lawal M. O., Olorunlana O. (2014) Risk perception and Marital Adjustment in HIV/AIDS among Federal Civil Servants. Journal of research and development 5, vol. 2. 
[21] Yomi Akindele-Oscar (2009). Condom use and multiple partnered sex among sexually active undergraduates in a Nigerian University. The African Symposium, Vol. 9, No 2.

[22] Serai Daniel Rakgoasi and Clifford Odimegwu (2013). "Women Get Infected but Men Die ...!" Narratives on Men, Masculinities and HIV/AIDS in Botswana International Journal of Men's Health, Vol. 12, No. 2,. 2013, 166-182.

[23] Adeolu M. O., Akinyemi J. O., Akpa O. M., Issa K. and Bamgboye E. A (2014). Wealth Status and Sexual Partnership Pattern among Nigerian Men. J. Med. Med. Sci. 5(9):208-217.

[24] Maharaj, P., (2001). Obstacles to Negotiating Dual protection: Perspectives of Men and Women. Afr. J. Reproduc. Health, 5(3): 150-161.

[25] Meekers, D. and Klein, M. (2001). Determinants of Condoms Use among Unmarried Youths in Yaoundé and Douala, Cameroon. PSI Research Division Working paper No 47. Population Service International, Washington DC, pp: 213246.
[26] UNAIDS (2014). The GAP Report 2014: Gay Men and other Men who have Sex with Men.

[27] Oladimeji, O., Bidemi, Y. O., Olufisayo, J. A., \& Sola, A. O. (2010). Prostate cancer awareness, knowledge, and screening practices among older men in Oyo State, Nigeria. Int Q Community Health Educ, 30(3), 271-286.

[28] Agyemang S, Buor D, Tagoe-Darko E (2012). The Extent of Knowledge about HIV/AIDS among Young people in the Ejura-Sekyedumase district of Ghana. J. AIDS HIV. Res. 4(11):241-7.

[29] Awosan, K. J., Ibrahim, M. T. O., Arisegi, S. A. and Erhiano, E. E. (2014). Knowledge of HIV/AIDS, risk perception, sexual lifestyle and condom use among drivers in Sokoto, Nigeria. Journal of Infectious Diseases and Immunity, Vol. 6(3), pp. 19-25. 